\title{
Exploration on the Innovative Design Course Promoting Industrial Design Teaching Reform
}

\author{
Xinghe Wang \\ College of Electromechanical Engineering and Automation \\ Liming Vocational University \\ Quanzhou, China
}

\author{
Yihui Zeng \\ English Education Department \\ Quanzhou Preschool Education College \\ Quanzhou, China
}

\author{
Yiping Tang \\ College of Electromechanical Engineering and Automation \\ Liming Vocational University \\ Quanzhou, China
}

\begin{abstract}
Starting with innovative design, this article analyzes the status quo of industrial design teaching, the application of innovative design course. Based on the analysis, it raises the great significance that the innovative design course brings to train talents of industrial design, summarizes three modes as improving practice in teaching, college-enterprise cooperation, diverse evaluation, aiming to promote the industrial design teaching reform, improve students' abilities of innovation and place a solid foundation for the students in relevant design work.
\end{abstract} reform

Keywords-innovative design; industrial design; teaching

\section{INTRODUCTION}

In Feb 2017, the Ministry of Industry and Information Technology and the Ministry of Finance jointly issued the "Instruction on Promoting the Development of Industry and Culture", pointing out that the industry is a base for a powerful country and the culture is a soul of a nation, and it is true that though China has become the world's largest manufacturing center, which however still looks large but not competent, and the deficiency in innovation is a key factor restricting the development[1]. Though it is related to the late start of industrial design, yet the largest restriction is the existing teaching system. Chinese education emphasizes the systematicness, coherence and integrity in the theory learning, and the practical teaching is kept in a lower proportion, the students are more passive to learn, which does no good to cultivate their abilities in innovation. In researches on the industrial design and innovative design courses at home, most are focused on the macro analysis or summary of strategic concepts and case experience of specific fields, for example, $\mathrm{Qu}$ Junlin [2] thinks that in order to develop enterprises, the product design capabilities must be improved, and the innovative development of industrial designs play a significant

Fund Program: Middle Age and Young Teachers Educational Scientific Research Program of Fujian Educational Department (JAT160835); General project of Liming Vocational University in 2017(LW201704). role in driving the enterprises. Chen Xiaohang [3] analyzes types and existing researches of common shopping carts, and innovative design courses are reflected in the new generation of multi-functional shopping carts. Some researchers propose to promote the industrial design teaching reform via design competitions, Wang Yanmin [4] takes the design competitions as carriers to explore the cultivation mode of industrial design innovation courses and students' abilities in innovation. Few researchers integrate the innovative design courses to industrial design teaching from the perspective of methodology. This article will explore the innovative design courses promoting the industrial design teaching reform via three methods namely teaching methods, teaching means and evaluation modes.

\section{INCREASE PRACTICES IN TEACHING}

The industrial design education in colleges and universities should keep an active interaction with the market, a well going mechanism for the connection between education and industry shall be established so as to put the students' abilities of innovation and comprehension fully into the practice [5]. Art is from but beyond life, so it is a must for designers to get rich practical experience. During the industrial design teaching reform, the proportion of practice shall be increased properly, which is mainly reflected in the design competition and research activities.

\section{A. Driven by Design Competitions}

In recent years, authorities have been attaching great importance to the industrial design, and the industrial design competitions are in a blowout, which are generally divided into three kinds: competitions sponsored by authorities and associations, industrial competitions, small-scale design competitions. Generally speaking, the competitions sponsored by authorities and associations are held with the highest standard, the highest level and the largest scale, such as China Excellent Design Award, China Innovative Design Red Star Award, China Industrial Design Top Ten Award and so on; industrial competitions are generally led by famous enterprises, 
diverse in form but limited in profession, such as Sannuo Cup China Industrial Design Competition, China (Wuyi) Electric Tools Design Competition and the like; small-scale design competitions are generally launched by colleges, universities or enterprises in order to cope with the design educational activities in there or small projects of enterprises.

Students are encouraged to participate in various design competitions according to professional levels of their own. For example, due to the limitations in professional software, freshman may participate in freehand sketching competitions such as "Haichen Zunyu Cup", "Haisi" creative painting competitions at Quanzhou, Hong Kong and Taiwan; With the improvement of professional skills, sophomore can participate in student-oriented design competitions, such as 2016 Quanzhou college students innovative and creative competition, Fujian college students cultural innovation and creative design competition and so on; With complete knowledge reserved, junior and senior students can participate in industrial design competitions, competitions sponsored by authorities and associations, such as 2016 Nationwide College Students Industrial Design Competition, Jianghuai Cup Industrial Design Competition, Furong Cup International Industrial Design Innovation Competition and so on. Generally the industrial design competitions are free, which will cause no financial pressure to students. Besides, the design competitions, while focusing on improving students' abilities of innovation, also require teachers to cultivate students' abilities of design and production via new technologies, new processes and new materials, putting the what students have learned to the practice.

\section{B. Driven by Scientific Research Activities}

Scientific researches play an important role in encouraging teachers and researchers to carry out scientific researches and academic innovation activities, raising the overall level of scientific research, ensuring the quality of education and teaching, promoting the colleges' development and driving the local economy, and students should be supported to participate in teachers' longitudinal and horizontal topic researches. Longitudinal topics refer to projects of educational committee, educational department, science and technical bureau and even colleges; horizontal topics mainly refer to the cooperation projects between teachers and enterprises. During the period, through screening and design, teachers take the initiative to introduce topics or cooperation projects, through practical projects, the students' theoretical knowledge and comprehensive quality will be tested; The practical projects will improve students' interests in learning, enable them to fully exert what they can do, active in the project survey and market feasibility reports, which will greatly improve the abilities and self-confidence in innovation; and the market opens a new application channel through the students' design practices, ultimately a sound connection and interaction between teachers, students and markets are achieved.

\section{TEACHING MEANS OF COLLEGE-ENTERPRISE COOPERATION}

During the innovation design courses promoting the industrial design teaching reform, we should be focused on college-enterprise cooperation, seeking ways for mutual benefits and win-win, so as to form a sound circle, which is summarized to two points namely "Invitation and Promotion".

\section{A. Invitation}

Invite and cope with enterprise design requirements to carry out relevant courses reforms. During the course, first of all, make a detailed program and hold special mobilization, invite enterprises' technicians to introduce relevant products and knowledge, if possible, just organize students to visit in the enterprises concerned. During the whole innovative design, teachers and enterprise personnel shall be present and offer students instructions in each design code. When training students' innovation consciousness and abilities, it shall be always focused on the economic construction and industrial development, aiming at enterprise product development and technical upgrade, active to participate in the technical innovation in enterprises, and striving to form an interactive mechanism between technical needs of enterprises and technical innovation in colleges[6].

\section{B. Promotion}

Colleges shall be devoted to the regional industrial development needs and creating unique brands. Take Quanzhou as an example, in May 2016, Quanzhou People's Government issued the "Practical Opinions on Promoting the Connection of Vocational Education with Industrial Needs during the 13th Five-Year Plan, raising to support the professional group construction of training badly-needed talents for industries with creative design included. Quanzhou is famous for unique industries such as clothing, shoes and apparels, stones, sanitary products, so the innovative design courses in this region should be based on characteristics of the industry with proper supports so as to better serve the local industry and make it popular in consumers. Besides, it shall actively participate in shows and exhibitions, make foreign enterprises know the college specialties, students' advantages, forming an advantage of bands, for example, attend the crossstrait college design shows, national vocational college students' skills and works exhibitions and the like.

\section{Diverse Evaluation Modes}

The innovative design courses promoting the industrial design teaching reform should be focused on students' interests and requirements of competitions and projects, instruct and collect data at the beginning of the class, and add design competition contents or enterprise projects according to the teaching plans of courses, instruct students to participate in the design of related works, and the evaluation modes shall not be limited to some specific form, but rely on the modern higher education theory, integrate theories to the practice and keep a close connection with the development needs of disciplines [7], make full use of time in and after class, and train students' interests in learning and self confidence via all kinds of innovative practice activities, making the students capable of acquiring knowledge and information, and ultimately improving the students' abilities of innovation and use of what they have learned. It can be the quality of competition works, the degree of enterprise's recognition or 
design patent, utility model patents and even invention patents. The diversity of evaluation modes will do good to improve students' divergent creative thoughts, multi-level achievements, and also play an important role in supervising and testing teachers' teaching quality and achievements.

\section{CONCLUSION}

Innovation is the first driving force for development with human-oriented. The first social function and fundamental value of higher education is reflected by the talent training, especially the training of innovative talents. During the innovative design courses promoting the industrial design teaching reform, we should follow the characteristics of industrial design discipline, create a professional training model with local characteristics, reform teaching contents reasonably, carry out the teaching methods to improve the practice, increase the teaching means for college - enterprise cooperation, encourage diverse evaluation modes, raise the teaching quality, promote the upgrade of students' abilities in innovative design so as to meet the needs of the local economic development.

\section{REFERENCES}

[1] Gao Mingjing, Zheng Chunlei, Industrial Design Becomes a Key Point for Industrial Cultural Development According to Instructions by Two Ministries [J/OL].China Industrial Newspaper, Feb 6, 2017. http://mp.weixin.qq.com/s/FlEYC_xZro58q0atK3LB2w

[2] Qu Junlin, Discussion on Ways for Industrial Design Innovation and Development [J] Manager's Journal, 2016 (3) : 201.

[3] Chen Xiaohang, Xu Min, Innovative Design of Multi-Functional Shopping Carts [J] Applied Science \& Technology 2016 (12) : 96-97.

[4] Wang Yanmin, Guo Maoglai, Jiang Xiao, Industrial Design Competition and Training of Students' Abilities in Innovation, taking Jiaxing University as an example [J] Popular Science \& Technology, 2012 (4) : 210-212.

[5] Zhu Mei, Research on Training of Innovative Capabilities under the Background of Creative Industry [J] Science Education Articles Collects, 2014 (A) : 99-100.

[6] Zhou Ji, Innovation and High-Level University Construction, Lecture at Forum of the 3rd Chinese and Foreign College Presidents Summit, 2016.

[7] Lin Wei, Liu Xiaohong, Exploring Teaching Modes of Innovative Design Courses [J]. Journal of Yunnan Arts Institute, 2017 (2) : 69-70. 